\title{
Effect of multi axis vibration and subject postures on sketching distortion
}

\author{
M.K. Bhiwapurkar*, V.H. Saran, S.P. Harsha \\ Mechanical and Industrial Engineering Department, Indian Institute of Technology Roorkee, INDIA \\ "Corresponding Author: e-mail: mbhiwapurkar@gmail.com, Tel +91-01332-285682, Fax. +91-01332-285665
}

\begin{abstract}
Sedentary activities such as reading, writing, sketching, etc. are affected due to the train vibrations. Therefore, the present study investigates the extent of perceived difficulty and distortion in a sketching task by seated subjects in two postures under low frequency, multi axial random vibrations. Thirty male voluntary subjects sketched geometric figures such as rectangles, circles and triangles in two sitting postures while exposed to multi-axis stimuli of vibration magnitudes $0.4,0.8$ and $1.2 \mathrm{~m} / \mathrm{s}^{2}$ r.m.s. in 1-20 Hz frequency range. Performance was evaluated both subjectively and objectively by two specifically designed objective methods. The deviation in distortion with respect to the given figures is represented in terms of percentage distortion. The percentage distortion and sketching difficulty increased with an increase in vibration magnitudes and was affected more while sketching on table. The sketching difficulty was found independent of geometric figures.
\end{abstract}

Keywords: whole body vibration, multi axis vibration, distortion in sketching.

\section{Introduction}

Studies of the whole-body vibration effects on activities have often focused on military personnel, with investigations of its effects on the vision or manual control of pilots and tank crew (Wollstrom, 2000). Moreover, tracking tasks have largely been used to determine the effect of vibration direction on task performance (Baker and Mansfield, 2010). There has been less attention given to the tasks performed by the general public as vehicle passengers. Exceptions are studies of the effects of vibration on drinking (Whitham and Griffin, 1978), effects of vibration on writing (Corbridge and Griffin, 1991; Westberg, 2000) and effects on reading (Griffin and Hayward, 1994; Sundström and Khan, 2008; Bhiwapurkar et al, 2010a). There are a number of studies (Griffin and Hayward, 1994; Corbridge and Griffin, 1986) on the effects of horizontal (X, Y-axis) vibrations, but none of these studies have been performed in trains or uses the similar vibration conditions as of in the trains. In a recent field study (Bhiwapurkar et al, $2010 \mathrm{c}$ ) on various Indian railway passenger trains which include both a questionnaire survey and vibration measurements reported that the maximum difficulty was found in writing activity (72\%), than working with laptop (58\%) and comparatively less with reading activity (56\%). The study reported that the vibration levels measured (unweighted) from floor of the passenger compartment found to be in the range of $0.2-0.67 \mathrm{~m} / \mathrm{s}^{2} \mathrm{rms}$ in longitudinal (X-axis) direction; $0.23-0.83 \mathrm{~m} / \mathrm{s}^{2} \mathrm{rms}$ in lateral (Yaxis) direction and $0.38-1.2 \mathrm{~m} / \mathrm{s}^{2} \mathrm{rms}$ in vertical (Z-axis) direction. Comparing quantitatively vibration with $\mathrm{X}$-axis, the vibration level was found to be about $30 \%$ higher in the Y-axis and approximately $80 \%$ higher in Z-axis. Therefore, these vibration magnitudes have been chosen for the study. The vibration transmitted will be affected by various parameters such as posture, vibration level, and frequency (Griffin, 1975). It was also reported that the human body motion under two directional random vibrations could not be approximated by superposition of one directional random vibration (Demic et al, 2002). The current trend in vibration research is to use multi axis values (Hinz et al, 2002; Paddan and Griffin, 2002). Lovesey (1970) also highlighted the importance of considering the effects of multi-axis vibrations rather than limiting the tests to single axis vibration.

Many people in metropolitan areas of India prefer to use trains for commuting to the work place. Daily commuters often desire to productively utilize their traveling time to carry out various sedentary activities like reading, writing, sketching etc. (Bhiwapurkar et al, 2010b). In such vibration environments, manually controlled movements by humans are known to be adversely affected. The present study is significant since it attempts to quantify the effect of vibrations on the writing ability in terms of performance impairment in sketching activity. The effect of vibrations on the ability to write cannot be quantified directly, whereas the 
difficulty experienced in working with the pen/pencil can be quantified in terms of the difficulty encountered in sketching activity. Simple geometric figures such as circles, rectangles and triangles were chosen for this study since they are independent of individual's skills. The objective of the study was to investigate the extent of perceived difficulty and distortion in a sketching task by seated subjects in two postures under low frequency, multi axial Gaussian random vibration environment. The subjective evaluation of the difficulty experienced to perform the task was obtained using Borg CR10 scale (Borg, 1998) and sketching performance was measured in terms of percentage distortion in sketching by specifically designed two objective methods such as RMS and Area method.

\section{Material and Methodology}

\subsection{Subjects}

Overall 30 healthy male subjects participated in the experiments with age in years $(22.91 \pm 4.58)$, weight $(68.91 \pm 12.04) \mathrm{kg}$ and height $(173.87 \pm 5.86) \mathrm{cm}$. All were engineering graduates, post graduates or research students of Indian Institute of Technology Roorkee, India having familiarity with drawing and sketching. All the subjects had normal eyesight (normal visual acuity $6 / 6$ vision). In direct association to the experiment, all subjects were required to fill in a questionnaire on their personal background: level of education; experience of traveling in trains; fitness; reading and writing habits; and musculoskeletal disorders (Kuorinka et al, 1987) to assure the suitability of the subjects for experimental task.

\subsection{Subject Posture}

In the laboratory study two main postures were investigated is shown (Figure 1). In the first seated posture referred as the lap posture, the seated person leans against the back of the seat, with the sketch material held on his lap. In the second seated posture mentioned as the table posture, the seated person leans forward at about $20^{\circ}$ w.r.t. vertical with the sketch material placed on the table. During experiment, the order the posture was random for all subjects.
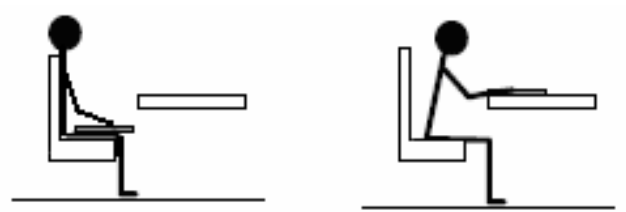

Figure 1. Subject postures used in the study

The two subject postures were chosen based on previous studies (Bhiwapurkar et al, 2010c; Sundström and Khan, 2008) which reported that a majority of train passengers preferred to adopt either of the two seated postures for writing activity. The experiments were conducted using a rigid seat with a configuration representative of that used for Indian train passenger compartment seats. The chair consisted of a $42 \times 42 \mathrm{~cm}^{2}$ flat seat and the height of the seat from floor was $48 \mathrm{cms}$.

\subsection{Vibration Environment}

The study was conducted on the vibration simulator developed as a mockup of railway vehicle, in the Vehicle Dynamics Laboratory of IIT Roorkee, India. It consists of a platform on which a table and two rigid chairs have been securely fixed (Figure 2). The backrest of the chair was rigid, flat, and vertical. The seat, the backrest, and the table are not in resonance condition within the frequency range studied (up to $20 \mathrm{~Hz}$ ) in any of the three axes. Three Electro-Dynamic Vibration shakers are used to provide vibration stimuli simultaneously to the platform in three translation axes viz, longitudinal (X), lateral (Y) and vertical (Z) direction. For simplicity and safety reasons, the internal positioning accelerometers of the shakers were continuously used for motion feedback. The onboard vibrations of the platform were measured on line for continuous monitoring of the vibration signal by using a tri-axial accelerometer 'A' (KISTLER 8393B10), the signal transmitted to the Labview Signal Express software via a data acquisition card (NI 6218).

The simulator provides a controlled train atmosphere with a working illumination well above 250 lux using both direct and indirect light sources for constant and well-distributed illumination at all seats and tables. The test subjects were seated on the chairs rigidly mounted on the platform of vibration simulator such that these are excited with the same frequency as the platform, up to the frequency range of interest. This range is considered critical, since it coincides with the most vulnerable range for writing activity and perhaps for sketching activity as well. 


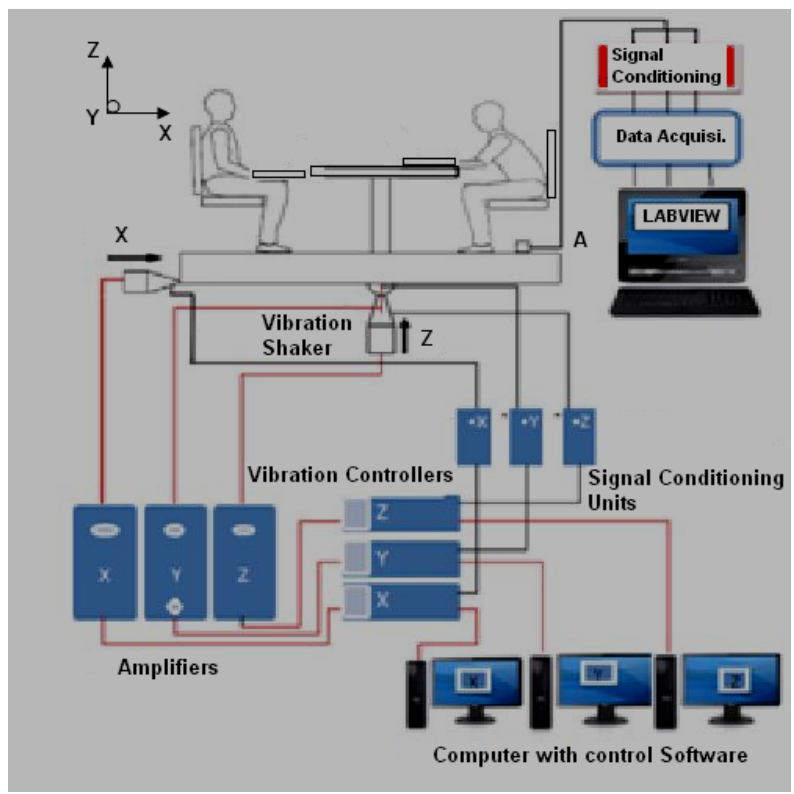

Figure 2. Schematic presentation of the equipment used for vibration measurements

\subsection{Vibration Stimuli}

In the study, for each sitting posture, a continuous random Gaussian signal over the frequency range 1-20 Hz was generated using random vibration controller for which the well-known exponential equation and bell-shaped curve defined the statistics. Power spectral density curve $\left(\mathrm{g}^{2} / \mathrm{Hz}\right)$ of the signal generated by the exciter over the frequency spectrum of interest is shown (Figure 3).

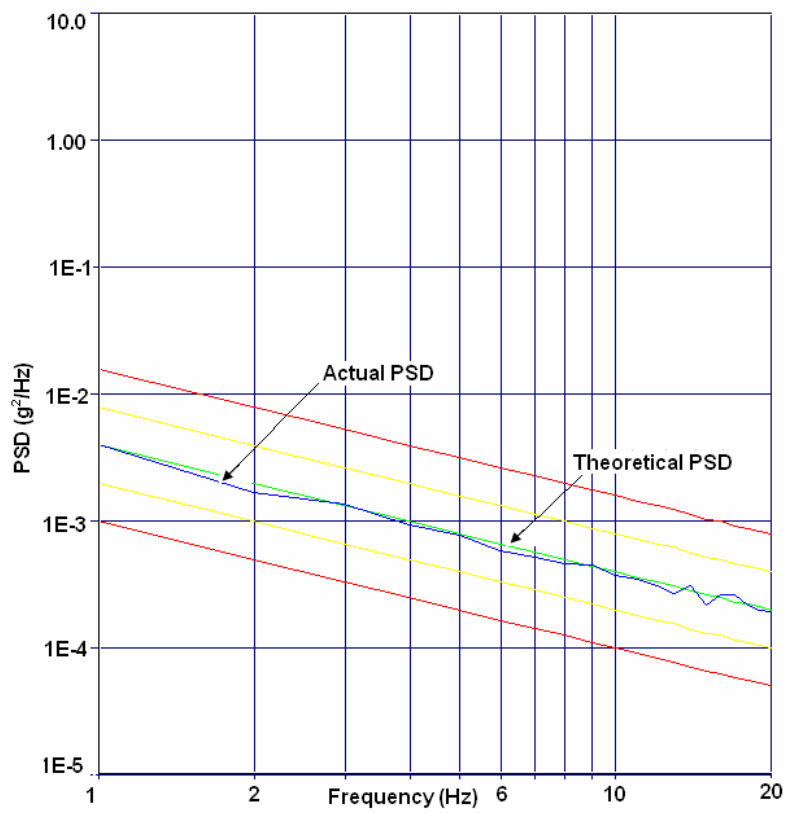

Figure 3. Power spectral density $\left(\mathrm{g}^{2} / \mathrm{Hz}\right)$ curve

The vibration level in Indian railway passenger train was found to be about 30\% higher in the Y-axis and approximately $80 \%$ higher in Z-axis in comparison with X-axis vibration. Therefore, in multi axis, three mono axes are excited simultaneously with above relation, which resulted in rss magnitudes of $0.4,0.8$ and $1.2 \mathrm{~m} / \mathrm{s}^{2}$ (unweighted), Table 1 . The RSS is the vibration total value which is obtained from the square root of the sum of the squares of the measured rms values in the X-, Y-, and Z- directions (Mansfield, 2005). To cover all the travel condition, vibration levels of $0.4,0.8$ and $1.2 \mathrm{~m} / \mathrm{s}^{2}$ were considered in the laboratory study. 
Table 1. Vibration levels in three axes acting simultaneously

\begin{tabular}{ccccc}
\hline \multirow{2}{*}{ Stimulus } & \multicolumn{4}{c}{ Vibration magnitude $\left(\mathrm{m} / \mathrm{s}^{2}\right.$ rms, unweighted $)$} \\
\cline { 2 - 5 } & X-axis & Y-axis & Z-axis & rss $\Sigma$ axes \\
\hline 1 & 0.17 & 0.22 & 0.3 & 0.4 \\
2 & 0.33 & 0.43 & 0.6 & 0.8 \\
3 & 0.5 & 0.63 & 0.9 & 1.2 \\
Static & - & - & - & - \\
\hline
\end{tabular}

rms $=$ root mean square; rss $=$ root sum of squares.

\subsection{Experimental Task}

The test subjects were seated two at a time in the vibration simulator and A4 size sheet printed with simple geometric figures such as circles, rectangles and triangles along with a Borg CR10 scale was provided. The subjects were asked to sketch on the given geometric figure with the help of a ball point pen without lifting the pen (Figure 4). Initially, the subjects were asked to sketch in a vibration-free environment (static). Next, the vibrations are imparted to the subjects seated in the vibration simulator and the subjects are required to repeat the same task for each vibration stimulus and posture.

Several authors have used time-based measures of activity performance, e.g. reading speed and reading error (Griffin and Hayward, 1994). Time-dependent measures are very conventional means of evaluating performance since it is known that slow readers are able to perform well in complicated tasks if only given adequate time (Nation, 2005). This ensured that the subjects' sketching ability had no influence on the outcome of the present study.

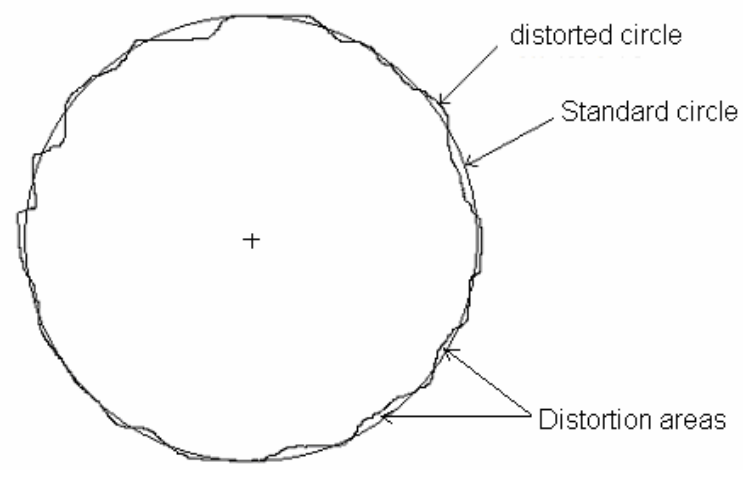

Figure 4. Comparison of geometrical figure with standard figure sketched under vibration

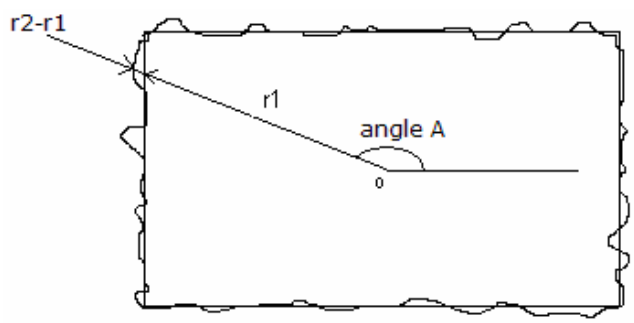

Figure 5. Radial difference for standard rectangle drawn by subject under vibrations

\subsection{Evaluation of distortion in sketching}

Two objective methods are proposed to evaluate the distortion in geometrical figures namely,

\subsubsection{Area Method}

In this method, the intersected area between the standard figure and the distorted figure is calculated. It is then divided by the area of the standard figure to normalize it. It can be expressed as percentage distortion. 


$$
\text { Percentage distortion }=\frac{\text { Area intersected between the standard figure and figure made by the subject }}{\text { Area of the standard figure }} \times 100
$$

\subsubsection{Root Mean Square Method (RMS method)}

In this method the difference between radial distance of the two figures (distorted and standard) from the center of standard figure at different angles was determined (Figure 5). Mathematically, the normalized RMS distortion can be expressed as:

$$
\text { Percentage RMS distortion }=\sqrt{\frac{\sum_{i=0}^{i=359.9}\left(\frac{r_{2}}{r_{1}}-1\right)^{2}}{3600}} \times 100
$$

The difference in radial distance was computed at intervals of 0.1 degrees for angles from 0 to 360 degrees, for good accuracy of evaluation. A Matlab program was developed to calculate the percentage distortion by both the objective methods.

From global perspective, paper documents (sketch), which are an inherently analog medium, can be converted into digital form by process of scanning. This process yields a digital image i.e. gray pixel. Using MATLAB programming the area of digital image of geometrical entity is selected. The distorted part of the area (Figure 4) is converted into black color (off pixels). The remaining area of the enclosed geometrical figure is kept white. This white area is measured in terms of number of "on pixels". The more number of "on pixels", the larger is the white area. Distorted area is considered positive whether inside or outside the standard geometrical entity. The area of standard geometrical entity (white area) is also to be measured to calculate percentage distortion. In RMS method, difference between pixel value in radial distance of the two figures (distorted and standard figure) from the center of standard figure at different angles were determined.

\subsection{Subjective Evaluation}

The subjective evaluation employed the Borg's CR-10 scale (Borg, 1998). Table 2 presents the Borg's CR-10 scale, which consists of 17 level points ( 9 labeled and 8 unlabeled). The scale is used by first finding the verbal label which best fits the stimulus attribute of interest, and then using the number scale to make adjustments to the rating. The value of 10 represents the maximum suggested intensity, but greater values can be chosen if the test participant so wishes. Due to its ease of use and reliability, the Borg's CR-10 scale has found wide application in the fields of physiology, psychology and ergonomics to rate sensations of pain, fatigue, physical exertion and discomfort (Pandolf et al., 1978; Ajovalasit and Giacomin, 2005).

Table 2: Borg CR10 scale (Borg, 1998)

\begin{tabular}{|cl|}
\hline $\mathbf{0}$ & Nothing at all \\
0.3 & \\
0.5 & Extremely weak (hardly noticeable) \\
0.7 & \\
1 & Very weak \\
1.5 & \\
\hline 2 & Weak (light) \\
2.5 & \\
3 & Moderate \\
4 & \\
\hline 5 & Strong (heavy) \\
6 & \\
7 & Very strong \\
8 & \\
9 & \\
10 & Extremely strong (almost maximal) \\
\hline$*$ & Absolute maximum \\
\hline
\end{tabular}

\subsection{Test Procedure}

Each subject began the experiment by filling out a general questionnaire about his personal information. This was followed by a brief introduction about the experiment to each subject. After obtaining their signatures on an informed consent, the subjects 
performed the experiment task. The study involved about 30 minutes of testing. Each subject was exposed to an overall 8 conditions, from a combination of three levels of vibration magnitudes and two types of subject postures with a 1-min break between consecutive sessions. A static condition with no vibrations was also used. The stimulus was presented randomly to minimize order effects. The test subjects were instructed to occupy themselves with the prescribed task during the vibration exposure and later on rate their perceived difficulty of sketching on Borg CR10 scale during the scheduled break.

\section{Data analysis}

At each vibration magnitude, the subjective and objective results were analysed using a Wilcoxon matched-pairs signed ranks test. This is the non-parametric equivalent of the paired sample t-test and was used with two columns of related (linked) data. The two-tailed test was used and statistical significance was accepted at $5 \%$ level $(p<0.05)$. The statistical package for social sciences (SPSS Inc., Chicago, USA, version 16) was used for statistical analysis.

\section{Results}

The detailed output response of 30 subjects for all the vibration conditions by both objective and subjective measure was given in Appendix I and II. To calculate the mean value, the average of all 30 subjects has been considered. The effect of vibration stimuli on mean perceived difficulty for all geometric figures in table posture is shown (Figure 6). Similarly, the mean values of all geometrical figures for 30 subjects are used to plot the level of difficulty (Figure 7), percentage distortion by RMS method (Figure 8) and percentage distortion by Area method (Figure 9) as a function of vibration magnitude for two seated postures.

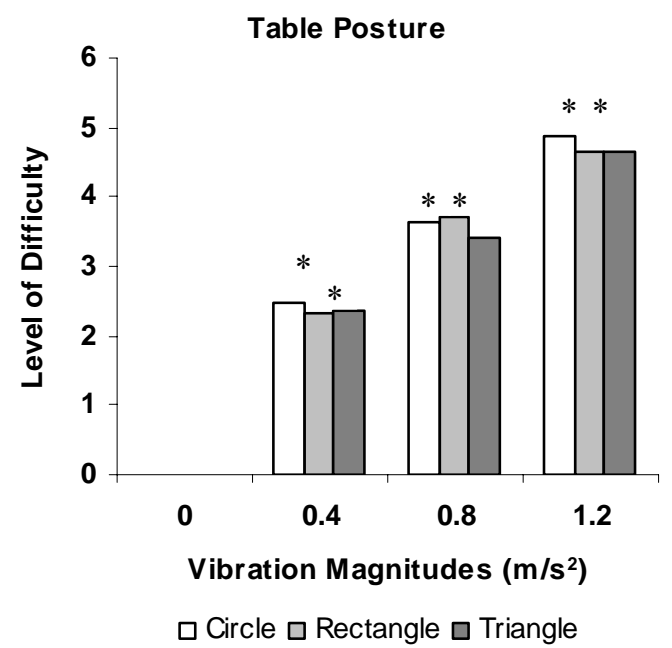

Figure. 6: Effect of vibration on mean perceived difficulty for all geometric figures in table posture (* indicates difference is insignificant i.e. $p>0.05$ )

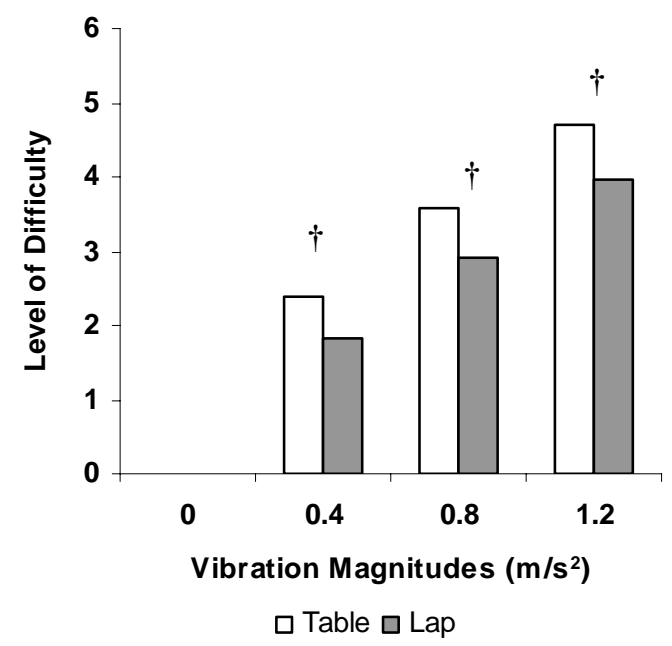

Figure. 7: Effect of vibration on mean perceived difficulty in both postures

$(†$ indicates difference is significant i.e. $p<0.05)$ 


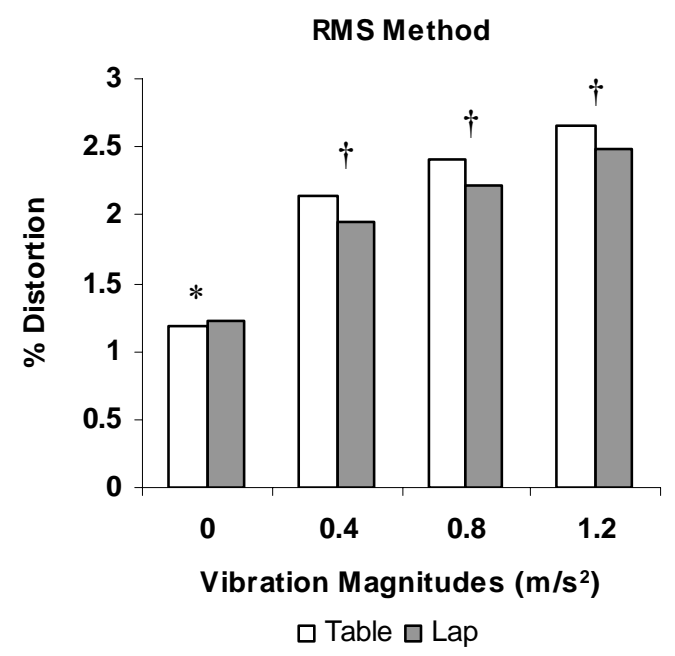

Figure. 8: Effect of vibration on mean percentage distortion in both postures by RMS method

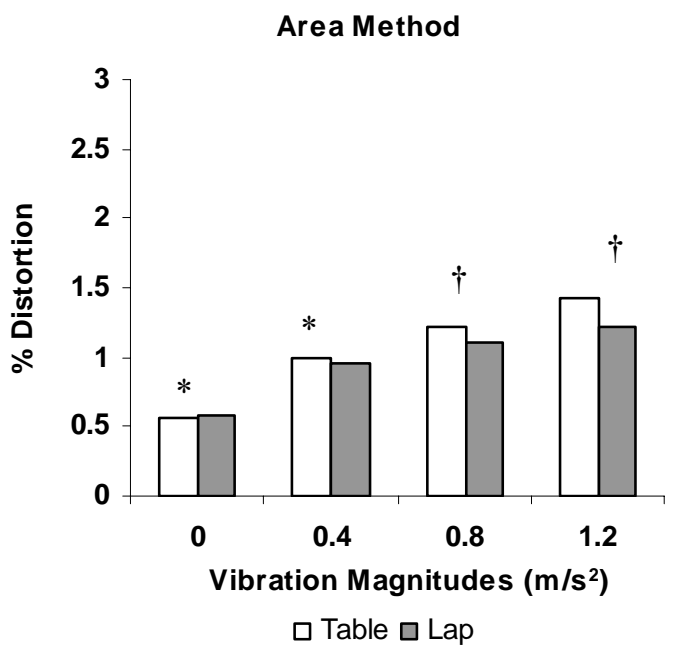

Figure. 9: Effect of vibration on mean percentage distortion in both postures by Area method

\subsection{Subjective evaluation of sketching difficulty}

The mean value of level of difficulty for all geometrical figures in multi axis vibration by subjective evaluation in table posture is shown (Figure 6). It can be observed that the level of difficulty of all geometrical figures progressively increases with an increase in intensity of vibration stimulus. It was also confirmed by observing statistically significant difference in level of difficulty between range of given vibration stimuli $(p<0.05)$. However, no significant difference in level of difficulty was observed among all geometrical figures at each vibration stimulus $(p>0.05)$, therefore, it was evident that there is no effect of the type of geometrical figures on the perceived difficulty to sketch.

Since the subjective evaluation revealed the independence in chosen entity $(p>0.05)$, the average values of percentage distortion for all the three geometrical figures have been considered (Figures 7 to 9). It was seen that the mean level of difficulty for all geometrical figures was found to increased with an increase in vibration stimuli in both the subject postures (Figure 7), also the difference in level of difficulty was found to be significant for each vibration stimulus in both the subject postures $(p<0.05)$. While comparing the subject's posture for perceived difficulty (Figure 7), the subject perceived more difficulty when the sketch pad is placed on the table as compared to that on the lap for all vibration stimuli $(\mathrm{p}<0.05)$.

\subsection{Objective task performance}

The mean percentage distortions by both objective methods for two subject postures are shown (Figures 8 and 9). The results obtained by the two methods of analysis show similar trend. Similar to subjective evaluation, the percentage distortion by both the objective methods was found to increased with an increase in intensity of vibration stimuli for both the seated posture, also the difference in level of difficulty was found to be significant for each vibration stimulus in both the subject postures $(p<0.05)$. The 
result shows that the percentage distortion obtained from RMS method was higher as compared to that of Area method, for both the subject postures, which could be attributed to the differences in mathematical definition of the two objective methods. While comparing the subject's posture for percentage distortion by both the objective method (Figures 7 and 8), the percentage distortion in sketching was found to be more when the sketch pad is placed on the table as compared to that on the lap. While the RMS method revealed higher percentage distortion in sketching on table posture at all vibration stimuli $(p<0.05)$, however, the Area method shows higher percentage distortion on table posture only at higher vibration stimuli (i.e. at 0.8 and $\left.1.2 \mathrm{~m} / \mathrm{s}^{2}\right)(p<0.05)$.

\section{Discussion}

The objective of the study was to quantitatively evaluate the distortion while sketching in vibration environment by two objective methods (Area and RMS method) and the obtained result is compared with the perceived difficulty assessed from subjective evaluation method. The results revealed that the perceived difficulty evaluated by subjective evaluation in sketching task was dependant on vibration stimuli and its degree of influence varied with vibration magnitude. The results are comparable with those of Mansfield and Maeda (2005), where subjective ratings of intensity increased with vibration magnitude for both single axis and dual axis vibration conditions. A similar outcome was also reflected in percentage distortion by both objective methods where percentage distortion in sketching increases with increase in vibration stimuli for both the subject's posture.

Previous studies (Corbridge and Griffin, 1991; Griffin and Hayward, 1994; Mansfield et al, 2007) have indicated that low levels of vibration in mono axes may not adversely affect task performance. However, the results from the present study (Figure 7) indicate that the moderate level of perceived difficulty in sketching task was observed even at lowest vibration stimulus (i.e. at 0.4 $\mathrm{m} / \mathrm{s}^{2}$ ). This could suggest that sketching tasks are more sensitive to multi axis vibration than mono axes. From the subjective evaluation and percentage distortion evaluated by both objective methods, the results revealed that the sketching performance was greatly hampered with sketch pad placed on table as compared to sketch pad on lap. The results of percentage distortion are comparable with those of subjective evaluation for subject postures.

The result for subject postures by Area method was found to be insignificant at lowest vibration stimulus $\left(0.4 \mathrm{~m} / \mathrm{s}^{2}\right)$ due to the difference in mathematical definition of the two objective methods. In a vibrating environment, the posture becomes even more important in suppressing and compensating the motions to limit their effect on the performance of the work. The posture has, thus, a vital role in transmitting vibrations to the different body segments, as well as to the working material. The significant difference in difficulty and distortion while sketching between the two subject postures used in this study could be explained by two different aspects, i.e. the support of the upper body and the vibration level of the working material. While working with the sketch pad placed on the lap, the upper body is supported by the back of the seat, and the legs are supported by the floor. Since the sketch pad is placed on the lap, it moves almost in phase with the body, hence difficulty level and percentage distortion are relatively found to be lower. On the other hand, with sketch pad placed on table, the upper body will be unsteady since it lacks support from the back of the seat and the sketch pad will oscillate along with the table. Due to the unsteadiness of the upper body the possibility is, thus, greater for the body to move out of phase with the table and material. While the sketching task is similar in both postures, the effect of posture is significant, which implies that posture has a stronger influence on the sketching performance. These results are similar to those found subjectively for writing activity (Sundström and Khan, 2008; Bhiwapurkar et al, 2010b).

The percentage distortion from RMS method was higher than that from Area method for both the subject postures, which could be attributed to the difference in mathematical definition of the two objective methods. It is also evident that the perceived difficulty in sketching task was not affected by the type of geometrical figures chosen. From the statistical results, good correlation was found between subject's self-judgment of sketching difficulty and the percentage distortion by RMS method. Therefore RMS method will be recommended for quantifying the percentage distortion. The ability to use various input devices is affected by motion, therefore, designers need to recognize the effects of motion and choose devices that account for those effects. Input tasks, such as cursor control, sketching, and using touch buttons, are affected by motion. While satisfactory performance may be realized in stationary conditions, similar inferences cannot be expected during motion. Since distortion in actual hand writing task was difficult to quantify, it was decided to study distortion in sketching simple geometric figures for which quantitative methods could be employed with relative simplicity, good degree of accuracy and repeatability.

None of the present standards used by the industry (ISO 2631-1, ENV 12299) considers the seated posture or the passengers' activity when evaluating ride comfort. These issues are necessary to emphasize since most of the train passengers are involved in sedentary activities and use trains as their working place. Presumably, adjustable table, better seat design and good track conditions might increase the performance of sedentary activities. Therefore, further studies are suggested to develop more appropriate weighting filters for the assessment of passenger discomfort with respect to the activities while traveling by train.

\section{Conclusions}

The present work is of high implication and relevance, since the passengers use most of their travelling time for performing sedentary activities. In this study, consisting of sketching activity in a mock-up of passenger's compartment, the performance measure for sketching activity in multi axis random vibrations have been investigated using subjective evaluation and two percentage distortion methods. It has been observed that the extent to which the percentage distortion and perceived difficulty was 
increased with an increase in vibration magnitudes. The results of subjective evaluation reveal that there is no effect of the type of entity chosen on the level of difficulty for the sketching activity. The results showed significant differences depending on postural conditions. The subjects reported greater difficulty while sketching with sketch pad on table than with sketch pad on the lap. The result from RMS distortion method found good correlation with subjective evaluation and is therefore recommended for quantifying the percentage distortion.

\section{Acknowledgement}

The financial assistance received from Department of Science \& Technology, New Delhi (India) for the research work is duly acknowledged. We also wish to thank all the participants for participating in the experiment and openly discussing their opinions.

\section{References}

Ajovalasit, M and Giacomin, J, 2005 Human subjective response to steering wheel vibration caused by diesel engine idle, Proc. IMechE. Part D: Journal of Automobile Engineering, Vol. 219, No. 4, pp. 499-510.

Baker, W.D.R. and Mansfield, N.J., 2010 Effects of horizontal whole-body vibration and standing posture on activity interference, Ergonomics, Vol. 53, No. 3, 365-374.

Borg, G., 1998, Borg's perceived exertion and pain scales. Human Kinetics Publishers, Champaign, IL.

Bhiwapurkar, M.K., Saran, V.H., Harsha, S.P., Goel, V.K. and Berg, M., 2010a, Influence of mono-axis random vibration on reading activity, Industrial Health, Vol. 48, pp. 675-681.

Bhiwapurkar, M.K., Saran, V.H., Harsha, S.P., Goel, V.K. and Berg, M., 2010b, Effect of magnitudes and directions (mono-axis and multi-axis) of whole body vibration exposures and subjects postures on the sketching performance. Proceedings of the Institution of Mechanical Engineers, Part F: Journal of Rail and Rapid Transit (In Press).

Bhiwapurkar, M.K., Singh, P. P., Yadav, J., Saran, V.H. and Harsha, S.P., 2010c, Influence of vibration on passenger comfort- A survey on Indian train, International Conference on Advances in Industrial Engineering Applications (ICAIEA 2010), Anna University Chennai, India,

CEN, 1999, Railway Applications-Ride Comfort for Passengers-Measurements and Evaluation (ENV 12299). CEN, Brussels.

Corbridge, C. and Griffin, M.J., 1986, Vibration and comfort: vertical and lateral motion in the range 0.5-5.0 Hz, Ergonomics, Vol. 29, No.2, pp. 249-272.

Corbridge, C. and Griffin, M.J., 1991 Effects of Vertical Vibration on Passenger Activities - Writing and Drinking, Ergonomics, Vol. 34, No.10, pp. 1313-1332.

Demic, M., Lukic, J. and Milic, Z., 2002, Some aspects of the investigation of random vibration influence on ride comfort, Journal of Sound and Vibration, Vol. 253, No.1, pp. 109-128.

Griffin, M.J. and Hayward, R.A., 1994, Effects of horizontal whole-body vibration on reading, Applied Ergonomics, Vol. 25, No.3, pp. 165-169.

Griffin, M.J., 1975, Vertical vibration of seated subject, effect of posture, vibration level, and frequency, Aviation Space and Environmental Medicine, Vol. 46, No.3, pp. 269-276.

Hinz, B., Seidel, H., Menzel, G. and Blüthner, R., 2002, Effects related to random whole-body vibration and posture on a suspended seat with and without backrest, Journal of Sound and Vibration, Vol. 253, No.1, pp. 265-282.

International Organization for Standardization, 1997, Mechanical Vibration and Shock: Evaluation of Human Exposure to WholeBody Vibration-Part 1: General Requirements (ISO 2631-1). International Organization for Standardization, Geneva.

Kuorinka, I., Jonsson, B., Kilbom, A., Vinterberg, H., Biering-Sørensen, F., Andersson, G. and Jørgensen, K., 1987, Standardised Nordic questionnaires for the analysis of musculoskeletal symptoms, Applied Ergonomics, Vol. 18, No.3, pp. 233-237.

Lovesey, E. J., 1970, The multi-axis vibration environment and man, Applied Ergonomics, Vol. 1, No.5, pp. 258-261.

Mansfield, N.J., 2005, Human response to vibration, 3rd Edition, CRC press, London.

Mansfield, N.J. and Maeda, S., 2005, Comparison of subjective ratings of whole-body vibration for single and multi-axis vibration, Proc. of 40th United Kingdom conference on human response to vibration, Liverpool, England.

Mansfield, N.J., Arora, Y. and Rimell, A., 2007, Computer use on moving trains: which pointing device? In: P. Bust, ed. Contemporary ergonomics, Taylor \& Francis, London, pp. 255-260.

Nation K., 2005, Children's reading comprehension difficulties. In M. Snowling \& C. Hulmes (Eds.). The science of reading:

A handbook: Malden, MA: Blackwell Publishing.

Paddan, G.S. and Griffin, M.J., 2002, Evaluation of whole-body vibration in vehicles, Journal of Sound and Vibration, Vol. 253, No.1, pp. 195-213.

Pandolf, K.B., 1978, Influence of local and central factors in dominating rated perceived exertion during physical work, Perceptual and Motor Skills, Vol. 46, pp. 683-698.

Sundström, J. and Khan, S., 2008, Influence of stationary lateral vibrations on train passengers' ability to read and write, Applied Ergonomics, Vol. 39, No.6, pp. 710-718. 
Westberg, J., 2000, Interference of lateral vibration on train passenger activities: an experiment on human ability to perform reading, writing and drinking, Master thesis, Royal Institute of Technology, KTH, Stockholm, Sweden.

Whitham, E.M., and Griffin, M.J., 1978, Interference with drinking due to whole-body vibration, Proceedings of the United Kingdom Informal Group on Human Response to Vibration, National Institute of Agricultural Engineering, Silsoe, Bedfordshire.

Wollstrom, M., 2000, Effects of vibrations on passenger activities: reading and writing - a literature study, TRITA -FKT Report 2000:64.

Appendix I: Response data of percentage distortion by both objective methods

\begin{tabular}{|c|c|c|c|c|c|c|c|c|c|c|c|c|c|c|c|c|}
\hline \multirow[t]{3}{*}{$\begin{array}{l}\text { Sub- } \\
\text { jects }\end{array}$} & \multicolumn{8}{|c|}{$\begin{array}{c}\text { Vibration magnitudes in both postures } \\
\text { (RMS Method) }\end{array}$} & \multicolumn{8}{|c|}{$\begin{array}{l}\begin{array}{l}\text { Vibration magnitudes in both postures } \\
\text { (Area Method) }\end{array} \\
\end{array}$} \\
\hline & \multicolumn{4}{|c|}{ Table } & \multicolumn{4}{|c|}{ Lap } & \multicolumn{4}{|c|}{ Table } & \multicolumn{4}{|c|}{ Lap } \\
\hline & 0 & 0.4 & 0.8 & 1.2 & O & 0.4 & 0.8 & 1.2 & $\mathbf{0}$ & 0.4 & 0.8 & 1.2 & O & 0.4 & 0.8 & 1.2 \\
\hline 1 & 15 & 18 & 18 & 26 & 1.4 & 1.4 & 1.7 & 2.2 & 0.4 & 0.7 & 1.1 & 1.2 & 0.6 & 0.8 & 1.0 & 0.6 \\
\hline 2 & 15 & 24 & 25 & 26 & 1.4 & 2 & 2.4 & 2.5 & 0.3 & 1.2 & 1.4 & 1.8 & 0.4 & 1.2 & 1.1 & 1.4 \\
\hline 3 & 13 & 18 & 24 & 26 & 1.2 & 1.7 & 2.5 & 2.7 & 0.4 & 1.2 & 1.4 & 1.4 & 0.3 & 1.0 & 1.5 & 1.4 \\
\hline 4 & 8 & 20 & 24 & 26 & 1.3 & 1.7 & 2.5 & 2.4 & 0.3 & 0.6 & 0.8 & 1.0 & 0.3 & 0.8 & 1.4 & 1.0 \\
\hline 5 & 10 & 19 & 26 & 24 & 1 & 1.7 & 2.4 & 2.4 & 0.3 & 0.8 & 1.2 & 1.0 & 0.3 & 0.6 & 0.8 & 1.2 \\
\hline 6 & 13 & 18 & 26 & 30 & 1 & 2.5 & 1.8 & 2.7 & 0.6 & 1.0 & 1.4 & 2.0 & 0.3 & 1.2 & 0.6 & 1.4 \\
\hline 7 & 6 & 24 & 20 & 24 & 1.2 & 1.4 & 1.7 & 2.6 & 0.2 & 0.8 & 1.0 & 1.0 & 0.6 & 0.7 & 0.6 & 1.0 \\
\hline 8 & 11 & 20 & 28 & 30 & 1.3 & 2.2 & 2.4 & 2.5 & 0.9 & 1.0 & 1.4 & 2.0 & 0.8 & 1.2 & 1.4 & 1.4 \\
\hline 9 & 12 & 19 & 28 & 26 & 1.4 & 2.2 & 2.3 & 2.4 & 0.5 & 1.0 & 1.3 & 1.2 & 0.5 & 0.6 & 1.0 & 1.0 \\
\hline 10 & 12 & 19 & 21 & 24 & 1.4 & 1.9 & 2.1 & 2.4 & 0.5 & 0.8 & 1.2 & 1.0 & 0.4 & 1.1 & 1.4 & 1.3 \\
\hline 11 & 12 & 24 & 27 & 29 & 1.3 & 2.1 & 2.3 & 2.7 & 0.3 & 1.0 & 0.9 & 1.3 & 0.7 & 1.2 & 1.3 & 1.0 \\
\hline 12 & 12 & 23 & 21 & 22 & 1.2 & 1.9 & 2.4 & 2.4 & 0.8 & 0.9 & 1.2 & 1.0 & 0.8 & 1.2 & 1.3 & 1.2 \\
\hline 13 & 10 & 20 & 22 & 24 & 0.9 & 1.9 & 2.2 & 2.5 & 0.6 & 0.9 & 1.2 & 1.8 & 0.4 & 0.7 & 0.8 & 1.3 \\
\hline 14 & 10 & 24 & 28 & 30 & 0.8 & 1.7 & 2.3 & 2.4 & 0.4 & 1.2 & 1.5 & 1.6 & 0.5 & 0.8 & 1.3 & 1.4 \\
\hline 15 & 11 & 20 & 20 & 22 & 1 & 2.1 & 2.4 & 2.7 & 0.6 & 1.0 & 1.2 & 1.0 & 0.8 & 0.9 & 1.1 & 1.2 \\
\hline 16 & 15 & 25 & 24 & 27 & 1.3 & 2 & 2.2 & 2.5 & 0.7 & 1.2 & 1.4 & 1.8 & 0.6 & 0.8 & 1.2 & 1.4 \\
\hline 17 & 12 & 20 & 22 & 28 & 1 & 2.2 & 2.5 & 2.5 & 0.4 & 1.0 & 1.0 & 1.8 & 0.5 & 0.8 & 1.2 & 1.4 \\
\hline 18 & 11 & 18 & 25 & 27 & 1.2 & 2.2 & 2.1 & 2.4 & 0.3 & 1.0 & 1.3 & 1.5 & 0.4 & 1.1 & 1.0 & 1.1 \\
\hline 19 & 10 & 20 & 23 & 30 & 1.3 & 2.2 & 2.4 & 2.7 & 0.3 & 0.8 & 1.0 & 1.6 & 0.4 & 1.2 & 1.1 & 1.4 \\
\hline 20 & 12 & 22 & 18 & 28 & 1 & 2.5 & 2.5 & 2.7 & 0.6 & 1.1 & 1.5 & 1.8 & 0.6 & 1.2 & 1.2 & 1.4 \\
\hline 21 & 10 & 25 & 29 & 30 & 1.2 & 2.5 & 2.5 & 2.7 & 0.7 & 1.1 & 1.2 & 1.4 & 0.5 & 1.2 & 1.1 & 1.4 \\
\hline 22 & 18 & 24 & 30 & 22 & 1.7 & 2 & 2.2 & 2.5 & 0.8 & 1.2 & 1.5 & 1.2 & 0.9 & 1.1 & 1.2 & 1.4 \\
\hline 23 & 10 & 18 & 22 & 27 & 1.1 & 2.1 & 2 & 2.2 & 0.6 & 0.9 & 1.2 & 1.8 & 0.8 & 0.8 & 1.0 & 1.0 \\
\hline 24 & 13 & 25 & 22 & 25 & 1.5 & 1.8 & 2 & 2.3 & 0.7 & 1.2 & 1.1 & 1.2 & 0.8 & 0.9 & 1.0 & 1.1 \\
\hline 25 & 10 & 25 & 24 & 26 & 1 & 2 & 2.1 & 2.4 & 0.8 & 1.0 & 1.2 & 1.3 & 0.6 & 1.2 & 1.0 & 1.2 \\
\hline 26 & 13 & 22 & 21 & 22 & 1.2 & 1.6 & 2.1 & 2.4 & 0.8 & 1.1 & 1.1 & 1.3 & 0.8 & 0.9 & 0.8 & 1.1 \\
\hline 27 & 12 & 20 & 20 & 26 & 1 & 1.6 & 1.8 & 2.4 & 0.8 & 0.9 & 1.1 & 1.4 & 0.5 & 1.0 & 1.1 & 1.3 \\
\hline 28 & 12 & 22 & 30 & 30 & 1.3 & 1.9 & 2.2 & 2.7 & 0.5 & 1.1 & 1.5 & 1.7 & 0.7 & 1.0 & 1.0 & 1.3 \\
\hline 29 & 11 & 21 & 24 & 28 & 1.1 & 2 & 2.2 & 2.4 & 0.6 & 1.2 & 1.0 & 1.1 & 0.8 & 1.0 & 1.2 & 0.9 \\
\hline 30 & 16 & 23 & 30 & 30 & 1.8 & 1.7 & 2.2 & 2.4 & 0.6 & 1.0 & 1.4 & 1.8 & 0.9 & 0.7 & 1.2 & 1.4 \\
\hline
\end{tabular}




\section{Appendix II: Response data of 30 subjects for perceived difficulty in sketching}

\begin{tabular}{|c|c|c|c|c|c|c|c|c|}
\hline \multirow{3}{*}{ Subjects } & \multicolumn{8}{|c|}{$\begin{array}{l}\text { Vibration magnitudes in both postures } \\
\text { (Subjective rating) }\end{array}$} \\
\hline & \multicolumn{4}{|c|}{ Table } & \multicolumn{4}{|c|}{ Lap } \\
\hline & $\mathbf{0}$ & 0.4 & 0.8 & 1.2 & $\mathbf{0}$ & 0.4 & 0.8 & 1.2 \\
\hline 1 & 0 & 2.5 & 4 & 6 & 0 & 2.5 & 4 & 5 \\
\hline 2 & 0 & 2.5 & 4 & 6 & 0 & 2.5 & 3 & 4 \\
\hline 3 & 0 & 3 & 4 & 5 & 0 & 2 & 3 & 5 \\
\hline 4 & 0 & 2 & 2 & 5 & 0 & 2.5 & 3 & 5 \\
\hline 5 & 0 & 2 & 2 & 3 & 0 & 2 & 2 & 3 \\
\hline 6 & 0 & 2 & 2 & 3 & 0 & 2 & 2 & 3 \\
\hline 7 & 0 & 3 & 4 & 6 & 0 & 2.5 & 3 & 4 \\
\hline 8 & 0 & 2.5 & 4 & 6 & 0 & 2.5 & 4 & 5 \\
\hline 9 & 0 & 2.5 & 4 & 5 & 0 & 2 & 3 & 4 \\
\hline 10 & 0 & 3 & 4 & 5 & 0 & 2 & 3 & 4 \\
\hline 11 & 0 & 3 & 4 & 5 & 0 & 1.5 & 3 & 4 \\
\hline 12 & 0 & 3 & 4 & 5 & 0 & 1.5 & 3 & 4 \\
\hline 13 & 0 & 3 & 4 & 3 & 0 & 1 & 2 & 4 \\
\hline 14 & 0 & 3 & 4 & 3 & 0 & 2 & 2 & 3 \\
\hline 15 & 0 & 3 & 4 & 3 & 0 & 2 & 2 & 3 \\
\hline 16 & 0 & 3 & 4 & 6 & 0 & 2 & 3 & 4 \\
\hline 17 & 0 & 2.5 & 4 & 5 & 0 & 1 & 4 & 5 \\
\hline 18 & 0 & 2.5 & 4 & 6 & 0 & 1.5 & 3 & 4 \\
\hline 19 & 0 & 2 & 4 & 5 & 0 & 2 & 3 & 4 \\
\hline 20 & 0 & 2 & 4 & 3 & 0 & 1 & 3 & 4 \\
\hline 21 & 0 & 2 & 2 & 3 & 0 & 1 & 3 & 4 \\
\hline 22 & 0 & 3 & 4 & 4 & 0 & 2 & 3 & 4 \\
\hline 23 & 0 & 2 & 2 & 4 & 0 & 2.5 & 3 & 5 \\
\hline 24 & 0 & 2 & 4 & 4 & 0 & 2 & 3 & 4 \\
\hline 25 & 0 & 2 & 4 & 5 & 0 & 1.5 & 3 & 3 \\
\hline 26 & 0 & 2 & 3 & 5 & 0 & 2 & 3 & 3 \\
\hline 27 & 0 & 2 & 4 & 5 & 0 & 1 & 3 & 3 \\
\hline 28 & 0 & 1.5 & 4 & 6 & 0 & 1 & 3 & 4 \\
\hline 29 & 0 & 1.5 & 3 & 5 & 0 & 2 & 3 & 5 \\
\hline 30 & 0 & 1.5 & 4 & 6 & 0 & 2 & 3 & 3 \\
\hline
\end{tabular}

\section{Biographical notes}

M.K. Bhiwapurkar is a research scholar and working as a senior research fellow under DST sponsored project "Effect of low frequency vibration to human comfort" in Mechanical and Industrial Engineering Department at Indian Institute of Technology Roorkee, India. He worked under EU-project on effect of low frequency vibration on activity comfort. His research areas are vibration and noise, biodynamic modeling, whole body vibration and ride comfort etc.

Dr. V.H. Saran is working as an assistant professor in Mechanical and Industrial Engineering Department at Indian Institute of Technology Roorkee, India. His research areas are Vehicle dynamics, vibration and noise, biodynamic modeling and low frequency vibration to human comfort. He is working for various national and International Research Projects such as DST, EU, SIDA etc.

Dr. Suraj P. Harsha is working as an assistant professor at MIED, IIT Roorkee, since May 2007. Before joining IIT Roorkee, he worked at CENDAC, Villanova University in Philadelphia, PA, U.S., for almost two year under a U.S. Defense- sponsored project as a post-doc fellow. He also worked as an assistant professor at BITS, Pilani, India, where he received his PhD. His research areas are nonlinear dynamics and chaos, vibrations and control, and unmanned surface/air vehicles.

Received August 2010

Accepted December 2010

Final acceptance in revised form December 2010 